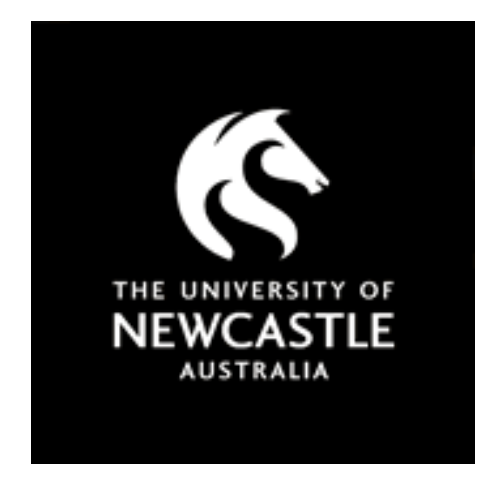

NOVA

University of Newcastle Research Online

nova.newcastle.edu.au

de Waal, Koert; Phad, Nilkant; Collins, Nick; Boyle, Andrew. "Cardiac remodeling in preterm infants with prolonged exposure to a patent ductus arteriosus", Published in Congenital Heart Disease Vol. 12, Issue 3, p. 364-372. (2017)

Available from: http://dx.doi.org/10.1111/chd.12454

This is the peer reviewed version of the above article, which has been published in final form at http://dx.doi.org/10.1111/chd.12454. This article may be used for non-commercial purposes in accordance with Wiley Terms and Conditions for Self-Archiving.

Accessed from: http://hdl.handle.net/1959.13/1353186 


\section{Cardiac remodeling in preterm infants with prolonged exposure to a patent ductus}

arteriosus

Koert de Waal ${ }^{1}$, Nilkant Phad ${ }^{1}$, Nick Collins ${ }^{2}$, Andrew Boyle ${ }^{2}$

1. John Hunter Children's Hospital department of Neonatology and University of Newcastle, Newcastle NSW, Australia

2. John Hunter Hospital department of Cardiology and University of Newcastle, Newcastle NSW, Australia

Correspondence to:

Dr Koert de Waal

Department of Neonatology

John Hunter Children's Hospital

Lookout road, New Lambton NSW 3205

Australia

Phone: $+61-2-49214362$

Fax: $+61-2-49214408$

Email: koert.dewaal@hnehealth.nsw.gov.au

Keywords: patent ductus arteriosus, echocardiography, speckle tracking, cardiac remodeling, cardiac function

All authors declare that they have no conflict of interest

This study was kindly supported with a grant from the John Hunter Hospital charitable trust fund. 


\begin{abstract}
Background

Sustained volume load due to a patent ductus arteriosus leads to cardiac remodeling. Remodeling changes can become pathological and are associated with cardiovascular disease progression. Data on remodeling changes in preterm infants is not available.
\end{abstract}

Methods

Clinical and echocardiography data were collected in preterm infants $<30$ weeks' gestation on postnatal day 3 and then every 7 to 14 days until closure of the ductus arteriosus. Images were analysed using conventional techniques and speckle tracking. Remodeling changes of infants with prolonged (>14 days) exposure to a patent ductus arteriosus were compared to control infants without a patent ductus arteriosus.

Results

Thirty out of 189 infants had prolonged exposure to a patent ductus arteriosus. The left heart remodeled to a larger and more spherical shape and thus significantly increased in volume. Most changes occurred in the first 4 weeks, plateaued, and then returned to control values. Systolic function and estimates of filling pressure increased and effective arterial elastance reduced with a patent ductus arteriosus, however contractility was unchanged. Wall thickness increased after 4 weeks of increased volume exposure.

\title{
Conclusion
}

The preterm patent ductus arteriosus induces early and significant remodeling of the left heart. A compensated cardiac physiology was seen with preserved systolic function, suggesting adaptive rather than pathological remodeling changes with prolonged exposure to a patent ductus arteriosus. 


\section{Background}

A patent ductus arteriosus (PDA) is a common problem in very preterm infants. More than half of preterm infants less than 29 weeks' gestation develop clinical signs associated with a PDA or will have a PDA found on routine echocardiography. ${ }^{1}$ Most preterm infants will receive treatment, as early studies have shown an association between a PDA and major morbidity in very preterm infants. Pharmacological treatment with one or 2 courses of nonsteroidal anti-inflammatory drugs can reduce PDA patency up to $80 \%$ before the infants have reached 14 days of age. ${ }^{2}$ The remaining preterm infants who do not undergo PDA closure typically experience sustained volume overload until closure occurs. Surgical ligation can provide definite PDA closure, however, reports have shown that such intervention is associated with increased morbidity in preterm infants and should probably be reserved for selected cases. ${ }^{3,4}$ For remaining cases, awaiting spontaneous closure is an alternative approach to management. ${ }^{5}$

Although PDA pathophysiology has been extensively studied during the first few days of life, little is known in terms of how the preterm heart remodels with sustained changes in volume loading conditions during a period of rapid organ development in the neonatal intensive care setting. Ventricular remodeling refers to the structural changes of the heart in response to biomechanical stress from ischaemic or inflammatory events, or from pressure or volume overload conditions. ${ }^{6-8}$ Remodeling and the associated functional changes are initially an adaptive response to the new mechanical conditions, but when the injury or stress is sustained, these remodeling changes can become pathological and are associated with cardiovascular disease progression in adults and children. ${ }^{9-12}$ The aim of this study is to describe cardiac remodeling and associated functional changes in preterm infants with sustained volume overload due to prolonged exposure to a PDA.

\section{Methods}


Study population

After approval for this study was obtained from Hunter New England Local Health District human research ethics committee, we reviewed clinical and echocardiography data from all preterm infants $<30$ weeks' gestation. As part of routine clinical practice, echocardiography examinations were performed on day 3 after birth in all infants of this gestational age range. When a PDA was present, echocardiography examinations would be performed every 7 to 14 days until the PDA was closed or was less than $1.0 \mathrm{~mm}$ in diameter. For the purpose of this study we defined prolonged exposure to a PDA as infants who had more than 14 days exposure to a PDA with a diameter of at least $1.5 \mathrm{~mm}$ and where the PDA showed a pulsatile blood flow pattern. This PDA profile is associated with echocardiographic and clinical volume overload in preterm infants..$^{2,5}$

The control group consisted of preterm infants less than 30 weeks gestation that were not treated with mechanical ventilation or inotropic support, received an echocardiogram during the study period and did not have a significant PDA. Most control infants were investigated for a murmur or were unable to tolerate a trial off positive airway pressure support. Scans of control infants were eligible for analysis if they had a PDA $<1.5 \mathrm{~mm}$ on day 3 and $<1.0 \mathrm{~mm}$ thereafter without any other significant cardiac abnormalities. A foramen ovale $<3 \mathrm{~mm}$ was considered normal.

Infants were excluded from this study if they had significant additional congenital abnormalities with or without congenital heart disease.

Echocardiographic image acquisition and data analysis

A $12 \mathrm{MHz}$ phased-array transducer was used with an iE33 echocardiographic scanner (Philips Medical Systems, the Netherlands). Four chamber, long and short axis views were 
acquired according to the American Society of Echocardiography. ${ }^{13}$ Two to four cardiac cycles triggered by the $R$ wave were stored at acquired frame rate (typically $90-110 \mathrm{~Hz}$ ).

The ductus arteriosus diameter and flow pattern were assessed according the methodology of Evans et al. ${ }^{14}$ Left and right ventricular outputs (LVO and RVO) were calculated from the cross sectional area of the respective valve annulus, velocity time integral and heart rate. A LVO:RVO ratio was calculated as indication of PDA shunt volume.

Remodeling changes were assessed by measuring parameters of cardiac dimensions, wall thickness, cardiac shape and cavity size. Left ventricle (LV) length (LV major axis from the 4 chamber view) and LV internal diameter (LV minor axis dimension in short axis view) were taken at end diastole. Relative wall thickness (RWT) was calculated from $(2 \times$ posterior wall thickness) / LV internal diameter in diastole of the short axis images. Cardiac shape was assessed with a sphericity index, defined as the end diastolic LV internal diameter divided by the LV length. A ratio closer to 1.00 indicates increased sphericity.

Cavity sizes were measured by tracing the inner dimension of the left atrium (LA) and the endocardial border of the LV from the apical 4 chamber images. LA area was estimated by manually tracing the left atrium with exclusion of the appendage and pulmonary veins at end systole and LA volume was calculated using a monoplane summation of disks method. The endocardial border of the LV was manually traced using speckle tracking software (Cardiac Performance Analysis, version 1.1; TomTec Imaging Systems, Germany). Speckle tracking is a novel non-Doppler technique that uses computer software to track and follow speckles generated by the 2D image from frame to frame, and allows for calculation of segmental and global parameters of motion (velocity, displacement) and deformation (strain and strain rate). With the trace placed on to the endocardial border, speckle tracking allows for a semiautomated method to determine maximum and minimum LV cavity size and calculate end diastolic and end systolic volumes using a monoplane summation of disks method. A detailed description of our methodology of the speckle tracking parameters has been 
published previously. In this study the inter and intra-observer correlation coefficient for deformation and LV volume parameters ranged from 0.78 to $0.94 .{ }^{15}$

Cardiac function was assessed by conventional and speckle tracking parameters. Systolic function was assessed by reviewing changes in cavity size (ejection fraction, EF), changes in inner dimensions (fractional shortening, FS), basal myocardial velocities during peak systole $\left(V_{L}\right.$ systole) and longitudinal peak systolic strain and strain rate $\left(S_{\mathrm{L}}, \mathrm{SR}_{\mathrm{L}}\right)$.

Diastolic function was assessed by measuring the rate of volume changes over the mitral valve, basal myocardial velocities during diastole ( $V_{L}$ early diastole and $V_{L}$ atrial contraction), and a speckle tracking derived E/e' ratio as an estimate of LV filling pressure. ${ }^{15,16}$

The interaction between the LV and the arterial system was explored by assessing blood pressure and ventriculo-arterial coupling (VAC), a simplified estimate of cardiovascular efficiency. ${ }^{17,18}$ VAC is defined as the ratio of the arterial elastance (Ea, derived from end systolic pressure divided by stroke volume) to ventricular elastance (Ees, derived from end systolic pressure divided by end systolic volume). End systolic pressure was estimated from $0.9 \times$ systolic blood pressure.

Data on respiratory support, blood gas details, blood pressure and the use of cardiovascular medications were recorded at the time of echocardiography.

\section{Statistics}

We anticipated that the final data set would contain a variable number of echocardiography studies per patient and per time point due to PDA closure, transfer back to referral hospitals and newborn mortality. A linear mixed model analysis was used to assess the within subject effects over time using a fixed effect model with autoregressive covariate type. No repeat measure statistical tests could be performed for the control infants, as most were not longitudinally assessed. Multiple comparisons between the infants with a PDA and the 
control infants at each time point were determined using ANOVA with a post-hoc Bonferroni test. Statistical analyses were performed using SPSS version 21 and GraphPad version 6 with $p$ values $<0.05$ considered to indicate significance.

\section{Results}

During a 24-month study period, 189 infants $<30$ weeks were admitted to our unit of which 30 preterm infants had at least 14 days' exposure to a PDA. The antenatal demographics and clinical complications of the whole cohort and the infants with prolonged PDA exposure are presented in table 1. Postnatal dexamethasone was used in 4 PDA infants (12 studies) and diuretics in 4 PDA infants (10 studies).

The median PDA diameter for the 30 infants with a PDA was $2.1 \mathrm{~mm}$ (range 1.8 to $3.8 \mathrm{~mm}$ ). All were unsuccessfully treated with ibuprofen before 14 days of age. In 18 infants the PDA closed spontaneously at various time points after 14 days of age and 2 infants underwent surgical ligation of their PDA (week 5 and 8). Three infants in the PDA group died during the study period (week 4, 5 and 8 ) and 3 infants were transferred back to referral hospitals with a PDA still present (week 7 and 8), leaving 4 infants with an open PDA at the end of a 10 week exposure period. The echocardiography parameters are presented in tables 2 to 4 and in figure 1.

\section{The PDA and shunt volume}

The PDA diameter and the LVO:RVO ratio did not change significantly over a 10 week exposure period ( $p 0.195$ and $p 0.282$ respectively). The LVO:RVO ratio was significantly higher in the first weeks of PDA exposure compared to controls, suggesting a mean Qp:Qs ratio of 1.5 . With increasing exposure time, the LVO:RVO ratio reduced due to a combination of decreasing LVO and increasing RVO. 
Left ventricular length, LV diameter and posterior wall thickness increased over time in both PDA exposure and control group reflecting body growth. LV length and diameter were not significantly different between the groups, but cardiac sphericity was higher in the first 4 weeks of PDA exposure. Posterior wall thickness during diastole was significantly higher from 4 weeks of PDA exposure compared to controls, with an increase in relative wall thickness occurring subsequently.

\section{Cardiac volumes}

All cardiac volumes (LA volume, ESV, EDV) increased significantly over time in the infants with a PDA $(p<0.001)$, and were significantly higher compared to controls up until 8 weeks of PDA exposure. Most of the volume changes occurred in the first 4 weeks when chamber volumes reached a plateau.

\section{Systolic function}

Parameters representing peak systolic performance did not change during the study period $\left(V_{L}\right.$ systole $p$ 0.215, $S R_{L} p$ 0.495) and were comparable to control values. Systolic function as measured by EF and $S_{\llcorner}$was initially increased and then returned to control values over time.

\section{Diastolic function}

Early diastolic and atrial velocities of the basal segments of the left ventricle increased over time ( $\mathrm{p} 0.003$ and 0.014 respectively) but were not significantly different from control values. The E/e' ratio increased over time $(p<0.001)$ and was higher in infants with a PDA in the first 4 weeks of PDA exposure.

\section{Ventriculo-arterial interactions}

Systolic and diastolic blood pressures in the infants with a PDA increased over time $(p 0.017$ and 0.040 respectively) and were significantly lower compared to control values in the first 6 
weeks of volume overload. Ventricular elastance in PDA infants reduced over time ( $p$ 0.045), but was comparable to controls. VAC was lower in PDA infants due to a lower arterial elastance.

\section{Discussion}

This study describes cardiac remodeling changes and physiological adaptation during prolonged exposure to a PDA in preterm infants. Sustained volume overload from a PDA leads to significant changes in size and shape of the preterm left heart. The remodeling changes can be found early and peak at 4 weeks of volume overload, and then return to control values at the end of a 10 week exposure period. Although the absolute increase in left sided chamber size was significant (LA volume $+83 \%$, LV volume $+57 \%$ ), the relative increase is more difficult to estimate. The control infants without a PDA also showed an increase in heart size as one would expect with rapid growth and increased metabolic demand after preterm birth. However, it took the control infants approximately 4 weeks to reach the same LA and LV size as 3 day old infants with a PDA, suggesting much of the early increase in left heart size seen in infants with a PDA was due to remodeling.

The change in shape and size led to altered cardiac function, especially in the first 4 weeks of volume overload. Increased preload was followed by an increase in stroke volume, indicating that Frank-Starling mechanisms were intact. Estimates of LV filling pressure were higher, presumably because the less compliant preterm heart has limited capabilities in altering its diastolic properties at this gestational age. ${ }^{15,19}$ Cardiac function was preserved predominantly by increasing EF and base-to-apex wall shortening $\left(\mathrm{S}_{\mathrm{L}}\right)$. We expected a simple shift up the Frank-Starling curve with the increase in preload, but we could not demonstrate an increase in force of myocardial contraction. Parameters closely related to contractility such as $S_{L}$ and systolic myocardial velocity were not increased. ${ }^{20,21}$ These 
findings are consistent with previous reports, showing no effect of the PDA on contractility as measured by rate-corrected velocity of fibre shortening and wall stress at peak systole. ${ }^{22}$

One mechanism to achieve higher left heart stroke volume without increasing contractility is by lowering afterload. Arterial blood pressure and effective arterial elastance were lower in the PDA infants. Ventricular elastance was unchanged, resulting in decoupling of the ventricular and arterial system. Decoupling with increased VAC, characterised by increased arterial elastance and a decline in ventricular elastance as seen in adults with aging hearts, hypertension or septic shock is associated with decreased energy efficiency. ${ }^{23,24}$ However, decoupling with reduced VAC in the absence of changes in LV stiffness as found in infants with a PDA might act as an adaptive mechanism when the heart is not capable of increasing contractility to maintain function. It remains unclear if is this process occurs at the cost of metabolic efficiency.

A second mechanism to cope with the increased preload may be mechanical. Higher LV filling pressure will increase the left-to-right shunt through the foramen ovale. Although we did not measure blood flow velocity at the level of the foramen, we found that a foramen ovale with left-to-right shunt was present in almost all preterm infants with a PDA and that RVO was increased with prolonged exposure to a PDA, consistent with findings of others. ${ }^{25,26}$

Our findings suggest that cardiac function adapted to the increased preload and decreased afterload. The new equilibrium was noted after approximately 4 weeks, and coincided with an increase in wall thickness which may potentially reflect an attempt to normalise wall stress. This adaptive response can also be found in children and adults with a PDA. ${ }^{27}$ Interpretation of wall thickness changes was confounded, however, by the fact that 4 infants were exposed to postnatal dexamethasone which can induce hypertrophy in preterm hearts. ${ }^{28}$ 
The term cardiac remodeling was initially used to describe the prominent changes that occur after myocardial infarction, but current understanding of cardiac remodeling suggests a broader concept. ${ }^{6-10}$ Kehat et al. describe cardiac remodeling as the shared pathways in molecular, biochemical, cellular and mechanical events that collectively change the shape of the myocardium, irrespective of the underlying stimuli. Classification of remodeling is usually based on geometric shape changes, with a compensatory and adaptive phase to reduce wall stress and maintain output, followed by a pathological phase with wall thinning and loss of cardiac performance. Overall cardiac performance and wall thickness were maintained in all infants with a PDA, even in those infants who died or underwent surgical ligation. This would suggest that the remodeling changes were in the compensatory phase. Our hypothesis that the changes were not pathological to the heart is supported by the finding that all echocardiographic changes were reversible. Cardiac size and shape and function returned to control values within one week after PDA closure (data not shown).

Cardiac function, development and remodeling are strongly linked. During both cardiac development and homeostatic adaptation, cardiac tissues sense physical forces generated by the heartbeat and respond with changes in gene expression. ${ }^{29}$ The role of mechanical forces in shaping the heart during cardiovascular development has been studied in a variety of fetal models, but none are representative for the pressure and volume changes of a PDA. ${ }^{30}$ In mice with a surgically placed aortocaval shunt, volume load induces an increase in titin stiffness that can be beneficial and limit eccentric remodelling, but prolonged exposure to volume load leads to further unwanted microscopic changes of the heart. ${ }^{31,32}$ Our study cannot comment if remodeling led to altered microscopic cardiac structure. In a sheep model examining remodeling after pre-term birth, Bensley et al. found cardiac hypertrophy, altered cardiomyocyte maturation and increased collagen deposition with preterm birth with no effect on cardiomyocyte numbers. ${ }^{33}$ Additional effects of a PDA were not examined in this study. Volume overload in the adult heart is characterized by minimal fibrosis and a preferential addition of sarcomeric units in series to help preserve ventricular function. ${ }^{10}$ These units can 
increase the shortening capacity of the myocyte and thus maintain $E F$ and $S_{L}$, as found in our study.

Our study has several limitations. All volume measurements and deformation parameters were calculated from monoplane images and not from bi- or triplane images. This approach is uniformly practiced in speckle tracking research studies and echocardiography in preterm infants in an attempt to minimise handling time, but it is unclear if this approach affects accuracy.

The small sample of infants with prolonged exposure to a PDA, especially in the last few weeks, limits generalisation of the data. We also did not encounter any infant in clinical category 1 or 2 according to the Toronto PDA triaging system, and none of the infants included in this cohort had a PDA $>3.0 \mathrm{~mm}$ for more than 1 week. ${ }^{4}$ Of note, patients referred for surgical ligation in other studies had comparable pre-ligation findings of LV size and function, which might add to the generalisability of our data. ${ }^{25,26,34}$ We could not explore if the addition of non-steroidal anti-inflammatory drugs attenuated the process of remodelling. Ventricular dilation induces adrenergic and renin-angiotensinaldosterone activation. Non-steroidal anti-inflammatory drugs can inhibit aldosterone metabolism and possibly contribute to the changes found. ${ }^{35}$ Further studies are needed to describe signalling pathways of cardiac remodeling in preterm infants and how current treatments can interact.

In conclusion, PDA volume overload induces a marked increase in left heart size and altered shape with a compensated cardiac physiology and preserved systolic function. Our findings suggest that the cardiac remodeling as diagnosed with conventional and novel echocardiography techniques is adaptive rather than pathological. 


\section{Authors email and contributions}

koert.dewaal@hnehealth.nsw.gov.au Dr Koert de Waal, department of Neonatology, John Hunter Children's Hospital and University of Newcastle NSW, Australia. Dr de Waal was responsible for protocol development, image acquisition, data analysis, and author of the original draft of the manuscript.

Nilkant.Phad2@hnehealth.nsw.gov.au Dr Nilkant Phad, department of Neonatology, John Hunter Children's Hospital and University of Newcastle NSW, Australia. Dr Phad was responsible for image acquisition, data analysis, and critical revising of the manuscript.

Nicholas.Collins@hnehealth.nsw.gov.au Dr Nick Collins, department of Cardiology, John Hunter Hospital and University of Newcastle NSW, Australia. Dr Collins was responsible for image acquisition and critical revising of the manuscript.

Andrew.boyle@newcastle.edu.au Prof Andrew Boyle, department of Cardiology, John Hunter Hospital and University of Newcastle NSW, Australia. Prof Boyle was responsible for protocol development, data analysis, and critical revising of the manuscript.

All authors have seen and approved the submission of this version of the manuscript and take full responsibility for the manuscript. 


\section{Compliance with Ethical Standards}

All procedures performed in studies involving human participants were in accordance with the ethical standards of the institutional and/or national research committee and with the 1964 Helsinki declaration and its later amendments or comparable ethical standards. The necessary ethics committee approval was obtained from the ethical committee of the John Hunter Hospital in Australia. All echocardiography scans were performed as part of clinical practice, and informed consent was waived for this study.

Echocardiography data up to 4 weeks of age of 4 included patients has been reported in a previous paper. de Waal K, Phad N, Lakkundi A, Tan P. Cardiac Function After the Immediate Transitional Period in Very Preterm Infants Using Speckle Tracking Analysis. Pediatr Cardiol. 2016 Feb;37(2):295-303 


\section{Legend figure}

Mean(SD) of selected echocardiography parameters on the y-axis and PDA exposure time in weeks on the $x$-axis. Red lines represent the infants with prolonged exposure to a PDA and black lines represent the control infants. LVO:RVO ratio, left to right ventricular output ratio; LA volume, left atrium volume in $\mathrm{ml} / \mathrm{kg}$; EDV, end diastolic volume in $\mathrm{ml} / \mathrm{kg}$; PWTd, posterior wall thickness in diastole in mm; VAC, ventriculo-arterial coupling index; EF, ejection fraction in \%; $S_{L}$, longitudinal strain in \%
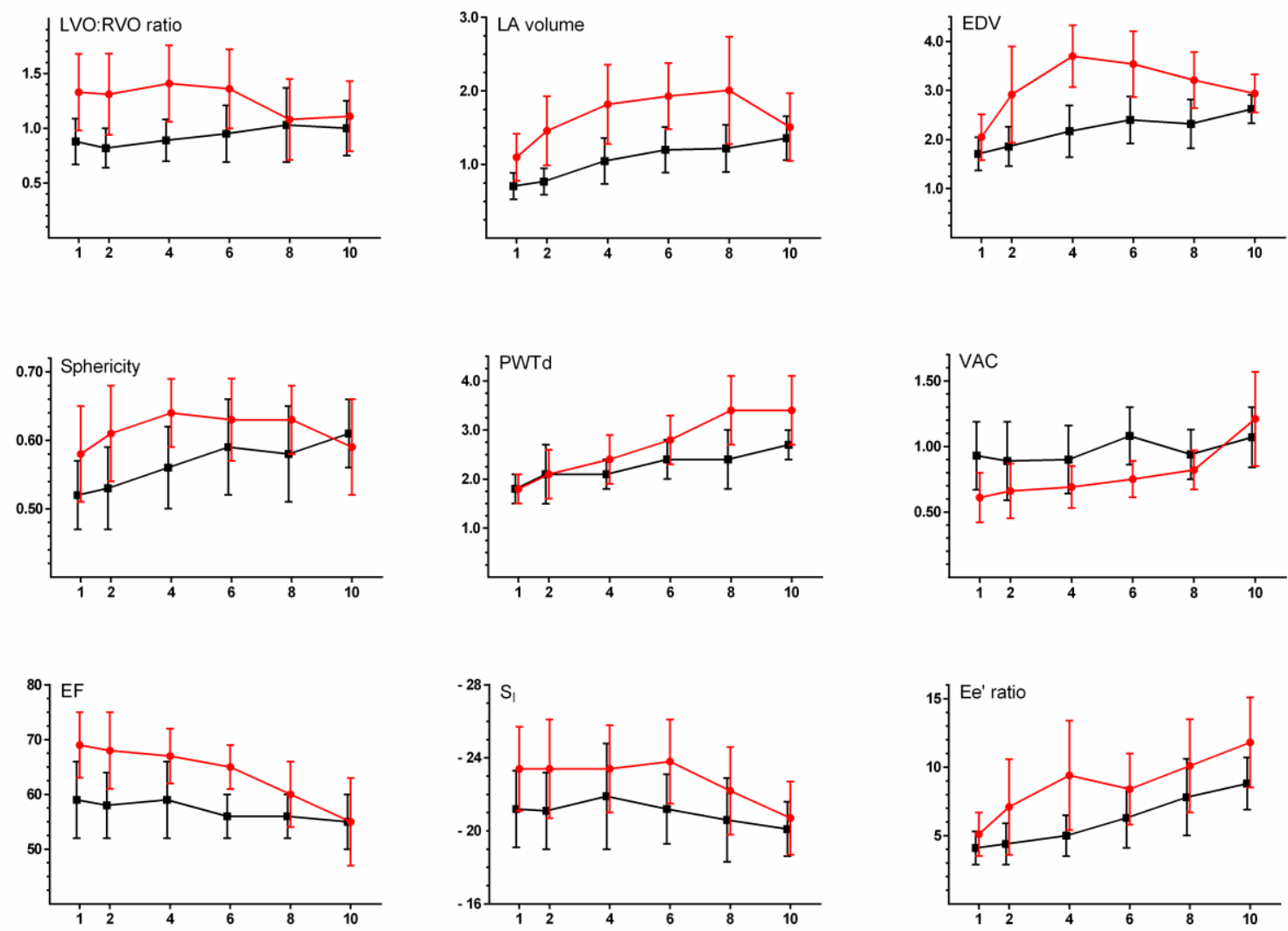



\section{References}

1. Hamrick SE, Hansmann G. Patent ductus arteriosus of the preterm infant. Pediatrics. 2010;125(5):1020-30

2. Jain A, Shah PS. Diagnosis, Evaluation, and Management of Patent Ductus Arteriosus in Preterm Neonates. JAMA Pediatr. 2015;169(9):863-72

3. Weisz DE, More K, McNamara PJ, Shah PS. PDA ligation and health outcomes: a metaanalysis. Pediatrics. 2014;133(4):e1024-46

4. El-Khuffash AF, Jain A, McNamara PJ. Ligation of the patent ductus arteriosus in preterm infants: understanding the physiology. J Pediatr. 2013;162(6):1100-6

5. Mitra S, Rønnestad A, Holmstrøm H. Management of patent ductus arteriosus in preterm infants--where do we stand? Congenit Heart Dis. 2013;8(6):500-12

6. Cohn JN, Ferrari R, Sharpe N. Cardiac remodeling--concepts and clinical implications: a consensus paper from an international forum on cardiac remodeling. Behalf of an International Forum on Cardiac Remodeling. J Am Coll Cardiol. 2000;35(3):569-82

7. Opie LH, Commerford PJ, Gersh BJ, Pfeffer MA. Controversies in ventricular remodeling. Lancet. 2006;367(9507):356-67

8. Knöll R, laccarino G, Tarone G, Hilfiker-Kleiner D, Bauersachs J, Leite-Moreira AF, et al. European Society of Cardiology. Towards a re-definition of 'cardiac hypertrophy' through a rational characterization of left ventricular phenotypes: a position paper of the Working Group 'Myocardial Function' of the ESC. Eur J Heart Fail. 2011;13(8):811-9

9. Hill JA, Olson EN. Cardiac plasticity. N Engl J Med. 2008;358(13):1370-80

10. Kehat I, Molkentin JD. Molecular pathways underlying cardiac remodeling during pathophysiological stimulation. Circulation. 2010;122(25):2727-35 
11. Tani LY, Minich LL, Williams RV, Shaddy RE. Ventricular remodeling in children with left ventricular dysfunction secondary to various cardiomyopathies. Am J Cardiol. 2005;96(8):1157-61

12. Singh AK, Ungerleider RM, Law YM. The Impact of Aortic Valve Replacement on Left Ventricular Remodeling in Children. Pediatr Cardiol. 2016;37(6):1022-7

13. Lopez L, Colan SD, Frommelt PC, Ensing GJ, Kendall K, Younoszai AK, et al. Recommendations for quantification methods during the performance of a pediatric echocardiogram: a report from the Pediatric Measurements Writing Group of the American Society of Echocardiography Pediatric and Congenital Heart Disease Council. J Am Soc Echocardiogr 2010;23(5):465-95

14. Evans N, lyer P. Longitudinal changes in the diameter of the ductus arteriosus in ventilated preterm infants: correlation with respiratory outcomes. Arch Dis Child Fetal Neonatal Ed 1995;72(3):F156-61

15. de Waal K, Phad N, Lakkundi A, Tan P. Cardiac function after the immediate transitional period in very preterm infants using speckle tracking analysis. Pediatr Cardiol. 2016;37(2):295-303

16. Dokainish H, Sengupta R, Pillai M, Bobek J, Lakkis N. Correlation of tissue Doppler and two-dimensional speckle myocardial velocities and comparison of derived ratios with invasively measured left ventricular filling pressures. J Am Soc Echocardiogr. $2009 ; 22(3): 284-9$

17. Chantler PD, Lakatta EG, Najjar SS. Arterial-ventricular coupling: mechanistic insights into cardiovascular performance at rest and during exercise. J Appl Physiol. $2008 ; 105(4): 1342-51$

18. Borlaug BA, Kass DA. Ventricular-vascular interaction in heart failure. Heart Fail Clin. 2008;4(1):23-36 
19. Hirose A, Khoo NS, Aziz K, Al-Rajaa N, van den Boom J, Savard W, et al. Evolution of left ventricular function in the preterm infant. J Am Soc Echocardiogr 2015;28(3):302-8

20. Weidemann F, Jamal F, Sutherland GR, Claus P, Kowalski M, Hatle L et al. Myocardial function defined by strain rate and strain during alterations in inotropic states and heart rate. Am J Physiol Heart Circ Physiol. 2002;283(2):H792-9

21. Greenberg NL, Firstenberg MS, Castro PL, Main M, Travaglini A, Odabashian JA, et al. Doppler-derived myocardial systolic strain rate is a strong index of left ventricular contractility. Circulation. 2002;105(1):99-105

22. Barlow AJ, Ward C, Webber SA, Sinclair BG, Potts JE, Sandor GG. Myocardial contractility in premature neonates with and without patent ductus arteriosus. Pediatr Cardiol. 2004;25(2):102-7

23. Chantler PD, Lakatta EG. Arterial-ventricular coupling with aging and disease. Front Physiol. 2012;3:90

24. Guarracino F, Baldassarri R, Pinsky MR. Ventriculo-arterial decoupling in acutely altered hemodynamic states. Crit Care. 2013;17(2):213

25. Noori S, Friedlich P, Seri I, Wong P. Changes in myocardial function and hemodynamics after ligation of the ductus arteriosus in preterm infants. J Pediatr. 2007;150(6):597-602

26. McNamara PJ, Stewart L, Shivananda SP, Stephens D, Sehgal A. Patent ductus arteriosus ligation is associated with impaired left ventricular systolic performance in premature infants weighing less than 1000 g. J Thorac Cardiovasc Surg. 2010;140(1):150-7 27. Schneider DJ. The patent ductus arteriosus in term infants, children, and adults. Semin Perinatol. 2012;36(2):146-53

28. Bensky AS, Kothadia JM, Covitz W. Cardiac effects of dexamethasone in very low birth weight infants. Pediatrics. 1996;97(6 Pt 1):818-21 
29. Andrés-Delgado L, Mercader N. Interplay between cardiac function and heart development. Biochim Biophys Acta. 2016;1863(7 Pt B):1707-16

30. Kowalski WJ, Pekkan K, Tinney JP, Keller BB. Investigating developmental cardiovascular biomechanics and the origins of congenital heart defects. Front Physiol. $2014 ; 5: 408$

31. Hutchinson KR, Saripalli C, Chung CS, Granzier H. Increased myocardial stiffness due to cardiac titin isoform switching in a mouse model of volume overload limits eccentric remodeling. J Mol Cell Cardiol. 2015;79:104-14

32. Ryan TD, Rothstein EC, Aban I, Tallaj JA, Husain A, Lucchesi PA, Dell'Italia LJ. Left ventricular eccentric remodeling and matrix loss are mediated by bradykinin and precede cardiomyocyte elongation in rats with volume overload. J Am Coll Cardiol. 2007:20;49(7):811-21

33. Bensley JG, Stacy VK, De Matteo R, Harding R, Black MJ. Cardiac remodeling as a result of pre-term birth: implications for future cardiovascular disease. Eur Heart J. 2010;31(16):2058-66

34. El-Khuffash AF, Jain A, Dragulescu A, McNamara PJ, Mertens L. Acute changes in myocardial systolic function in preterm infants undergoing patent ductus arteriosus ligation: a tissue Doppler and myocardial deformation study. J Am Soc Echocardiogr. 2012;25(10):1058-67

35. Knights KM, Mangoni AA, Miners JO. Non-selective nonsteroidal anti-inflammatory drugs and cardiovascular events: is aldosterone the silent partner in crime? $\mathrm{Br} \mathrm{J}$ Clin Pharmacol. 2006;61(6):738-40 


\begin{tabular}{|c|c|c|}
\hline & $\begin{array}{c}\text { Total cohort }<30 \text { weeks' } \\
\text { gestation } \\
(n=189)\end{array}$ & $\begin{array}{l}\text { Infants with prolonged } \\
\text { exposure to a PDA } \\
(n=30)\end{array}$ \\
\hline Any antenatal steroids & $181(96 \%)$ & $28(93 \%)$ \\
\hline Pregnancy induced hypertension & $31(16 \%)$ & $4(13 \%)$ \\
\hline Caesarean section & $103(54 \%)$ & $14(47 \%)$ \\
\hline Gestational age & 27 (23 to 29$)$ & 26 (23 to 29$)$ \\
\hline Birth weight & 925 (500 to 1670$)$ & 790 (500 to 1490) \\
\hline Male & $103(54 \%)$ & $16(53 \%)$ \\
\hline Small for gestational age $(<\mathrm{p} 5)$ & $18(10 \%)$ & $2(7 \%)$ \\
\hline Intraventricular haemorrhage grade 3 or 4 & $4(2 \%)$ & $0(0 \%)$ \\
\hline Died & $12(6 \%)$ & $3(10 \%)$ \\
\hline Necrotising enterocolitis stage $2 \mathrm{~b}$ or above & $8(4 \%)$ & $2(7 \%)$ \\
\hline $\begin{array}{l}\text { Retinopathy of prematurity receiving treatment } \\
\text { (in survivors) }\end{array}$ & $6(3 \%)$ & $3(11 \%)$ \\
\hline $\begin{array}{l}\text { Chronic lung disease at } 36 \text { weeks } \\
\text { (in survivors) }\end{array}$ & $66(37 \%)$ & $14(52 \%)$ \\
\hline
\end{tabular}

Table 1. Antenatal demographics and clinical complications of the total cohort of infants $<30$ week gestation during the study period and the 30 infants with prolonged ( $>14$ days) exposure to a PDA > $1.5 \mathrm{~mm}$. Data is presented as $\mathrm{n}(\%)$ or median (range) 


\begin{tabular}{|c|c|c|c|c|c|c|c|c|c|c|c|c|}
\hline & \multicolumn{2}{|c|}{ Day3 } & \multicolumn{2}{|c|}{ Week 1-2 } & \multicolumn{2}{|c|}{ Week 3-4 } & \multicolumn{2}{|c|}{ Week 5-6 } & \multicolumn{2}{|c|}{ Week 7-8 } & \multicolumn{2}{|c|}{ Week 9-10 } \\
\hline & pPDA & control & pPDA & control & pPDA & control & pPDA & control & pPDA & control & pPDA & control \\
\hline $\mathrm{n}$ & 30 & 77 & 30 & 42 & 23 & 35 & 11 & 25 & 9 & 18 & 4 & 12 \\
\hline PDA diameter $(\mathrm{mm})$ & 2.3(0.4)\# & $0.3(0.4)$ & 2.1(0.4)\# & $0.2(0.3)$ & $2.2(0.3) \#$ & $0.2(0.3)$ & 2.2(0.2)\# & $0.1(0.1)$ & $2.2(0.4) \#$ & $0.0(0.0)$ & $2.0(0.3) \#$ & $0.0(0.0)$ \\
\hline LVO (ml/kg/min) & 343(86)\# & 292(72) & $440(136) \#$ & $267(63)$ & 553(133)\# & $358(87)$ & 502(142)\# & $339(56)$ & 506(149)\# & $358(66)$ & 396(52)\# & $316(58)$ \\
\hline LVO:RVO ratio & 1.33(0.35)\# & $0.88(0.21)$ & $1.31(0.37) \#$ & $0.82(0.19)$ & 1.41(0.35)\# & $0.89(0.19)$ & $1.36(0.36) \#$ & $0.95(0.26)$ & $1.08(0.37)$ & $1.03(0.34)$ & $1.11(0.32)$ & $1.00(0.25)$ \\
\hline LV length $(\mathrm{mm})$ & $20.6(1.9)$ & $21.3(2.4)$ & $21.7(2.3)$ & $21.9(1.7)$ & $22.9(1.8)$ & $23.1(1.5)$ & $25.9(1.3)$ & 25.3(2.6) & $28.7(3.3)$ & $27.6(1.8)$ & $30.5(3.3)$ & $29.5(3.1)$ \\
\hline Sphericity index & $0.58(0.07) \#$ & $0.52(0.05)$ & $0.61(0.07) \#$ & $0.53(0.06)$ & $0.64(0.05) \#$ & $0.56(0.06)$ & $0.63(0.06)$ & $0.59(0.07)$ & $0.63(0.05)$ & $0.58(0.07)$ & $0.59(0.07)$ & $0.61(0.05)$ \\
\hline PWTd (mm) & $1.8(0.3)$ & $1.8(0.3)$ & $2.1(0.5)$ & $2.1(0.6)$ & $2.4(0.5) \#$ & $2.1(0.3)$ & $2.8(0.5)$ & $2.4(0.4)$ & $3.4(0.7) \#$ & $2.4(0.6)$ & $3.4(0.7) \#$ & $2.7(0.3)$ \\
\hline PWTs (mm) & $2.9(0.7)$ & $3.0(0.7)$ & $3.3(0.8)$ & $3.4(0.8)$ & 4.1(0.7)\# & $3.6(0.7)$ & $4.3(1.0)$ & $4.4(1.0)$ & $5.4(1.2)$ & $4.4(1.1)$ & $6.3(0.9)$ & $4.7(1.1)$ \\
\hline RWT & $0.26(0.03)$ & $0.28(0.05)$ & $0.28(0.08)$ & $0.32(0.10)$ & $0.28(0.06)$ & $0.29(0.05)$ & $0.35(0.11)$ & $0.32(0.09)$ & $0.39(0.15) \#$ & $0.26(0.06)$ & $0.39(0.15) \#$ & $0.26(0.03)$ \\
\hline FS (\%) & $37(10)$ & $35(9)$ & $37(9)$ & $37(9)$ & $39(9)$ & $39(8)$ & $39(9)$ & $36(8)$ & $41(9)$ & $35(9)$ & $49(7)$ & $37(8)$ \\
\hline LA volume $(\mathrm{ml} / \mathrm{kg})$ & $1.10(0.32) \#$ & $0.71(0.18)$ & $1.46(0.47) \#$ & $0.77(0.18)$ & $1.82(0.54) \#$ & $1.05(0.31)$ & 1.93(0.45)\# & $1.20(0.31)$ & 2.01(0.73)\# & $1.22(0.32)$ & $1.51(0.46)$ & $1.36(0.30)$ \\
\hline $\mathrm{ESV}(\mathrm{ml} / \mathrm{kg})$ & $0.63(0.15)$ & $0.72(0.22)$ & $0.97(0.48)$ & $0.78(0.24)$ & $1.22(0.31) \#$ & $0.92(0.38)$ & $1.26(0.36)$ & $1.06(0.28)$ & $1.27(0.25)$ & $1.02(0.28)$ & $1.34(0.36)$ & $1.15(0.11)$ \\
\hline $\operatorname{EDV}(\mathrm{ml} / \mathrm{kg})$ & $2.05(0.47) \#$ & $1.71(0.34)$ & 2.92(0.98)\# & $1.86(0.40)$ & $3.70(0.63) \#$ & $2.17(0.53)$ & $3.54(0.67) \#$ & $2.40(0.48)$ & $3.21(0.57) \#$ & $2.32(0.50)$ & $2.94(0.39)$ & $2.62(0.29)$ \\
\hline $\mathrm{EF}(\%)$ & 69(6)\# & $59(7)$ & 68(7)\# & $58(6)$ & 67(5)\# & $59(7)$ & 65(4)\# & $56(4)$ & $60(6)$ & $56(4)$ & $55(8)$ & $55(5)$ \\
\hline
\end{tabular}

Table 2. Mean(SD) of conventional echocardiography parameters. \# indicates a significant difference between prolonged exposure infants (pPDA) and controls. LVO, left ventricular output; RVO, right ventricular output; LV, left ventricle; PWTd, posterior wall thickness in diastole; PWTs, posterior wall thickness in systole; RWT, relative wall thickness; FS, fractional shortening; LA, left atrium; ESV, end systolic volume; EDV, end diastolic volume; EF, ejection fraction 


\begin{tabular}{|c|c|c|c|c|c|c|c|c|c|c|c|c|}
\hline & \multicolumn{2}{|c|}{ Day3 } & \multicolumn{2}{|c|}{ Week 1-2 } & \multicolumn{2}{|c|}{ Week 3-4 } & \multicolumn{2}{|c|}{ Week 5-6 } & \multicolumn{2}{|c|}{ Week 7-8 } & \multicolumn{2}{|c|}{ Week 9-10 } \\
\hline & pPDA & control & pPDA & control & pPDA & control & pPDA & control & pPDA & control & pPDA & control \\
\hline $\mathrm{n}$ & 30 & 77 & 30 & 42 & 23 & 35 & 11 & 25 & 9 & 18 & 4 & 12 \\
\hline $\mathrm{S}_{\mathrm{L}}(\%)$ & $-23.4(2.3) \#$ & $-21.2(2.1)$ & $-23.4(2.7) \#$ & $-21.1(2.1)$ & $-23.4(2.4)$ & $-21.9(2.9)$ & $-23.8(2.3) \#$ & $-21.2(1.9)$ & $-22.2(2.4)$ & $-20.6(2.3)$ & $-20.7(2.0)$ & $-20.1(1.5)$ \\
\hline SR $\mathrm{L}$ peak systole $(1 / \mathrm{s})$ & $-2.5(0.3)$ & $-2.4(0.4)$ & $-2.6(0.4)$ & $-2.4(0.4)$ & $-2.6(0.4)$ & $-2.5(0.5)$ & $-2.5(0.4)$ & $-2.3(0.3)$ & $-2.5(0.3)$ & $-2.3(0.3)$ & $-2.3(0.3)$ & $-2.1(0.2)$ \\
\hline $\mathrm{SR}_{\mathrm{L}}$ peak diastole $(1 / \mathrm{s})$ & $3.7(0.7)$ & $3.4(0.6)$ & $3.8(0.7) \#$ & $3.3(0.6)$ & $3.9(0.6) \#$ & $3.4(0.7)$ & $4.0(0.4)$ & $3.4(0.7)$ & $4.1(0.7)$ & $3.6(0.6)$ & $3.7(0.8)$ & $3.3(0.6)$ \\
\hline$V_{\mathrm{L}}$ systole $(\mathrm{cm} / \mathrm{s})$ & $2.5(0.4)$ & $2.4(0.4)$ & $2.8(0.4)$ & $2.5(0.4)$ & $2.9(0.4)$ & $3.0(0.4)$ & $3.0(0.4)$ & $2.9(0.4)$ & $3.0(0.5)$ & $2.9(0.4)$ & $3.0(0.6)$ & $3.0(0.5)$ \\
\hline $\mathrm{V}_{\mathrm{L}}$ early diastole $(\mathrm{cm} / \mathrm{s})$ & $2.5(0.8)$ & $2.8(0.7)$ & $2.7(0.8)$ & $2.9(0.7)$ & $3.0(0.6)$ & $3.0(0.6)$ & $3.6(0.9)$ & $3.4(0.7)$ & $3.6(1.3)$ & $3.3(0.5)$ & $3.2(0.8)$ & $4.4(0.9)$ \\
\hline $\mathrm{V}_{\mathrm{L}}$ atrial $(\mathrm{cm} / \mathrm{s})$ & $3.2(0.7)$ & $3.1(0.9)$ & $3.7(0.8)$ & $3.4(0.8)$ & $4.4(1.2)$ & $4.2(0.9)$ & $5.2(0.9)$ & $4.4(1.4)$ & $5.0(1.3)$ & $4.4(1.4)$ & $5.6(2.0)$ & $4.5(0.9)$ \\
\hline E/e' ratio & $5.1(1.6) \#$ & $4.1(1.2)$ & $7.1(3.5) \#$ & $4.4(1.5)$ & 9.4(4.0)\# & $5.0(1.5)$ & $8.4(2.6)$ & $6.3(2.2)$ & $10.1(3.4)$ & $7.8(2.8)$ & $11.8(3.3)$ & $8.8(1.9)$ \\
\hline
\end{tabular}

Table 3. Mean(SD) of speckle tracking derived echocardiography parameters. \# indicates a significant difference between prolonged exposed infants (pPDA) and controls. $S_{L}$, longitudinal strain; $S_{L}$, longitudinal strain rate; $V_{L}$, longitudinal velocity in the basal segments 


\begin{tabular}{|c|c|c|c|c|c|c|c|c|c|c|c|c|}
\hline & \multicolumn{2}{|c|}{ Day3 } & \multicolumn{2}{|c|}{ Week 1-2 } & \multicolumn{2}{|c|}{ Week 3-4 } & \multicolumn{2}{|c|}{ Week 5-6 } & \multicolumn{2}{|c|}{ Week 7-8 } & \multicolumn{2}{|c|}{ Week 9-10 } \\
\hline & pPDA & control & pPDA & control & pPDA & control & pPDA & control & pPDA & control & pPDA & control \\
\hline $\mathrm{n}$ & 30 & 77 & 30 & 42 & 23 & 35 & 11 & 25 & 9 & 18 & 4 & 12 \\
\hline $\mathrm{SBP}(\mathrm{mmHg})$ & 47(6)\# & $55(7)$ & 51(7)\# & $59(9)$ & $58(7) \#$ & $65(10)$ & 62(8)\# & $71(8)$ & $69(9)$ & $68(7)$ & $73(12)$ & $73(11)$ \\
\hline $\mathrm{DBP}(\mathrm{mmHg})$ & 25(5)\# & $32(7)$ & 26(6)\# & $34(7)$ & 29(8)\# & $38(8)$ & 30(5)\# & $36(6)$ & $34(4)$ & $36(6)$ & $40(9)$ & $37(6)$ \\
\hline $\mathrm{Ea}(\mathrm{mmHg} / \mathrm{ml} / \mathrm{kg})$ & 35(11)\# & $60(24)$ & 27(8)\# & $45(12)$ & 23(8)\# & $47(15)$ & 19(7)\# & $34(8)$ & 18(6)\# & $27(8)$ & $21(6)$ & $21(7)$ \\
\hline Ees $(\mathrm{mmHg} / \mathrm{ml} / \mathrm{kg})$ & $61(18)$ & $67(19)$ & $44(15)$ & $54(21)$ & $35(14) \#$ & $59(17)$ & $25(10)$ & $33(12)$ & $22(8)$ & $31(12)$ & $19(7)$ & $20(5)$ \\
\hline VAC & $0.61(0.19) \#$ & $0.93(0.26)$ & $0.66(0.21) \#$ & $0.89(0.30)$ & $0.69(0.16) \#$ & $0.90(0.26)$ & $0.75(0.14) \#$ & $1.08(0.22)$ & $0.82(0.15)$ & $0.94(0.19)$ & $1.21(0.36)$ & $1.07(0.23)$ \\
\hline
\end{tabular}

Table 4. Mean(SD) of arterial and ventricular interaction parameters. \# indicates a significant difference between prolonged exposed infants (pPDA) and controls. SBP, systolic blood pressure; DBP, diastolic blood pressure; Ea, arterial elastance; Ees, ventricular elastance; VAC, ventriculo-arterial coupling index. 